\title{
Teilnahmebedingungen
}

Für diese Fortbildungseinheit erhalten Sie drei Fortbildungspunkte. Hierfür

- müssen 7 der 10 Quiz-Fragen richtig beantwortet sein.

- müssen Seite 1 und Seite 2 des Evaluationsbogens vollständig ausgefüllt sein. Unvollständig ausgefüllte Bögen können nicht berücksichtigt werden!

- muss eine CME-Wertmarke im Feld D (Evaluationsbogen) aufgeklebt oder Ihre DMW-Abonnement-Nummer im Feld D eingetragen bzw. über das Internet eingegeben sein.

- Einsendeschluss ist der 17.2.2007

(Datum des Poststempels bzw. Datum der Online-Teilnahme). Die Teilnahme-Bescheinigungen für auf dem Postweg eingesandte Antwortbogen werden innerhalb von 3 Wochen nach Eingang im Verlag versandt. OnlineTeilnehmer erhalten eine direkte Rückmeldung mit der Möglichkeit, ein Teilnahme-Zertifikat auszudrucken. Von telefonischen Anfragen bitten wir abzusehen.

\section{Immunogene Myositiden}

\section{Eine und nur eine Antwort ist jeweils richtig!}

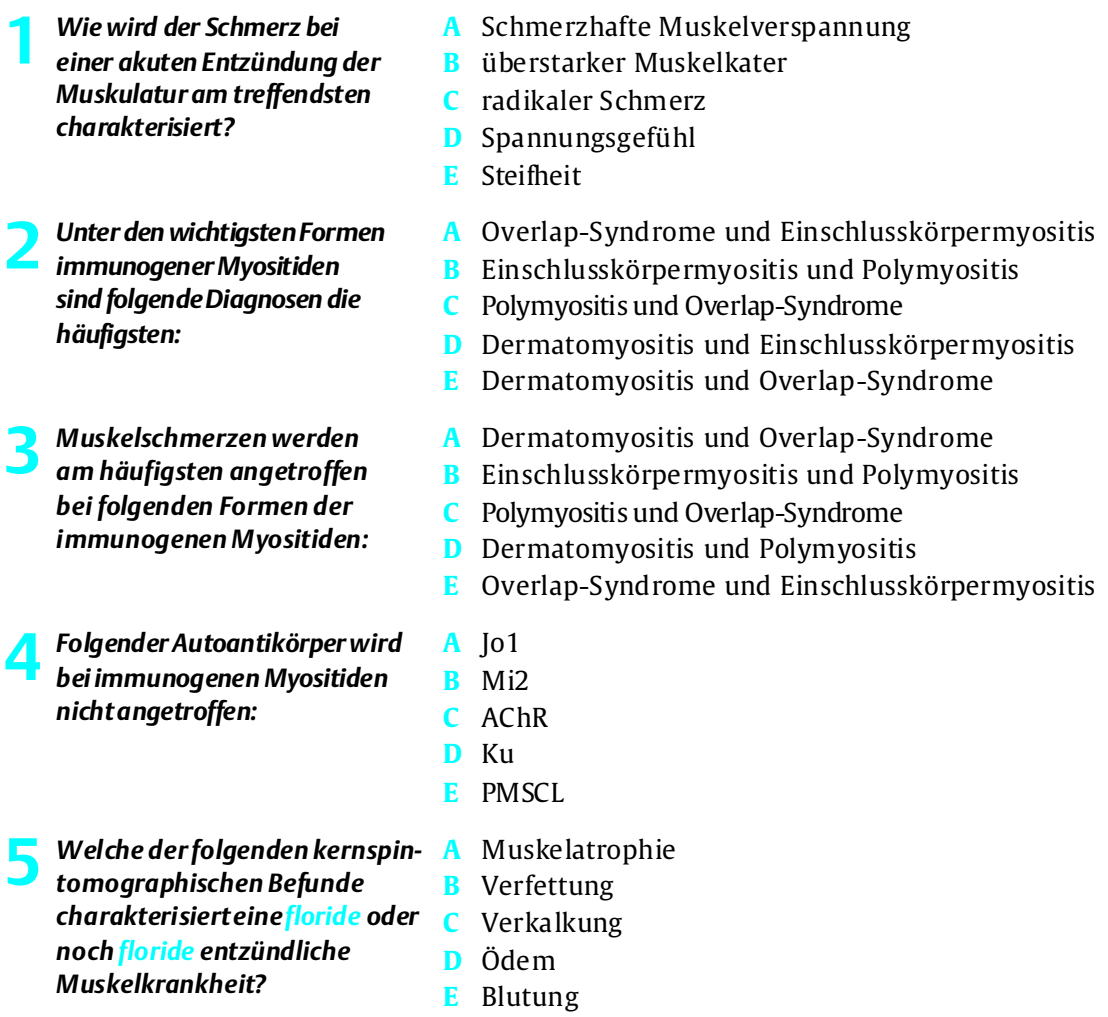




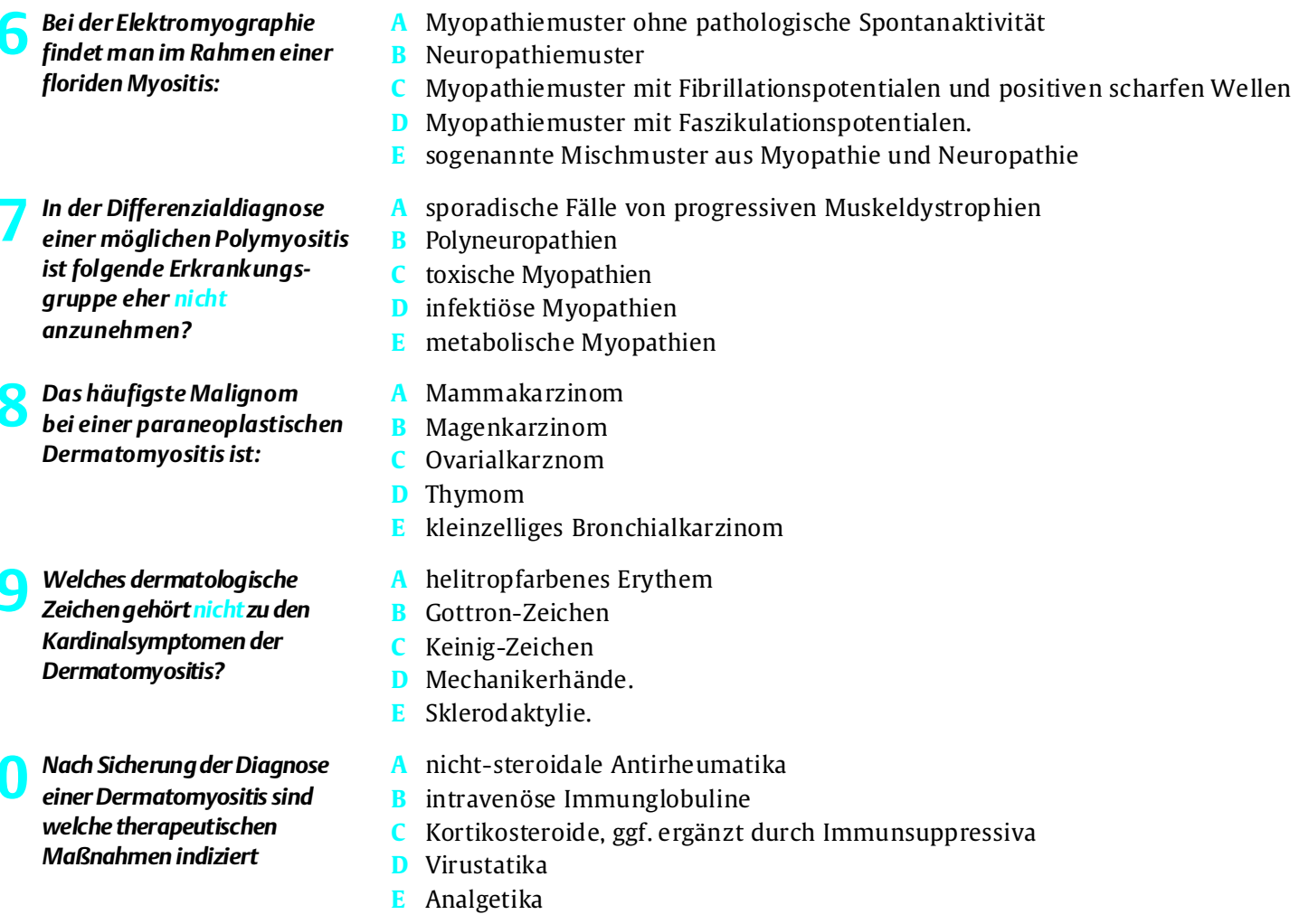

